\title{
PROCESSO DE ENFERMAGEM - APLICAÇÃO EM UMA UNIDADE DE HOSPITAL-ESCOLA DO INTERIOR
}

Maria Aparecida Fernandes*:

FERNANDES, M.A. Processo de enfermagem - aplicação em uma unidade de hospital-escola do interior. Rcv. Esc. Ens. USP, São Paulo, 21(n\%/especial):88-99, 1987.

\section{INTRODUÇAO}

O processo de enfermagem surgiu como um instrumento no planejamento e execução dos cuidados de enfermagem.

Conforme LEWIS ', o processo de enfermagem, pode ser a chave para o tipo de cuidado que caracteriza a enfermagem profissional, e pode asegurar que o cuidado de enfermagem tenha por finalidade 0 atendimento das necessidades do paciente.

Em 1965 foi oficialmente introduzido no programa de Fundamentos da Escola de Enfermagem da USP a história dos problemas de saúde do paciente - Anamnese de enfermagem que posteriormente recebeu o nome de Histórico de Enfermagem, (HORTA ${ }^{5}$ ). Desde então a metodologia do Processo de Enfermagem vem sendo ensinado e exigido dos alunos de graduação e Pós-Graduação de enfermagem.

Em nosso meio entretanto não se constitui em prática comum, o que tem preocupado não só os estudiosos do assunto, mas também as enfermeiras de campo, pois elas sentem de maneira mais objetiva a falta de uma padronização e orientação única no tratamento de enfermagem. Assim também, os alunos têm a idéia de que a Metodologia de Assistência é apenas um exercício acadêmico, pois mesmo no hospital, campo de estágio ela não é utilizada, sendo que vários fatores são responsabilizados por este fato.

Conforme ASHWORTH ${ }^{1}$, há alguns anos a reação de algumas enfermeiras frente ao Processo de Enfermagem era negativa e até hostil. Atualmente existe considerável interesse e entusiasmo, embora ainda observe-se relutância no seu uso como método de trabalho.

Embora verifique-se uma série de vantagens com a aplicação desta metodologia, o seu uso não é difundido, porque alguns abstáculos opõem-se à sua implementação.

O principal problema é a motivação. Apesar de saber-se que o caminho para o progresso se faz geralmente através de mudanças, elas não são benvindas em qualquer esfera da vida.

Enfermeira. Mestre em Enfermagem. Docente da Associação Municipal de Ensino Superior de Marilia. 
A motivação decresce e o interesse das enfermeiras se perde quando a mudança significa alguma atividade extra, embora o resultado seja em benefício de seu próprio trabalho.

Segundo COWPER-SMITH ${ }^{2}$, estrutura ocupacional tradicionalmente rigida seria um obstáculo importante à implantação do Processo de Enfermagem. Alguns profissionais sentem-se ameaçados quanto ao valor de seu próprio treinamento, seu status e senso de autoridade.

Outros experimentam medo e ansiedade sobre as novas tarefas que lhe serão exigidas, principalmente no que se refere à prescrição de enfermagem.

Há também, numa estrutura já organizada, a tendência de incorporar o Processo de Enfermagem a sistemas de informações já existentes.

O uso de roteiros para Histórico de Enfermagem ou sistemas de registros inadequados dificulta o sucesso do emprego da Metodologia de Assistência. Históricos de Enfermagem muito longos, com perguntas ambiguas ou com dados que posteriormente não serão utilizados, levam à perda de tempo e frustração.

O tempo ou a falta de tempo é uma queixa geral e um forte obstáculo citado por vários autores.

Equipes de enfermagem com número reduzido de pessoal, com preparo profissional inadequado, se constitui em importante obstáculo a ser vencido.

Dificuldade em aceitar e manipular as mudanças levam ao desgaste, frustração e insucesso. Toda mudança de método de trabalho exige abertura de pensamento, estudos e pesquisas até se encontrar o que melhor se adapte à situação.

$O$ requisito fundamental para que qualquer mudança se processe é que a enfermeira, ela mesma deve dar o exemplo de conhecimento, responsabilidade e atitude profissional. Deve estar convencida da necessidade e da importância do uso de uma Metodologia de Assistência de Enfermagem. vidades.

A partir dai ela pode iniciar um cuidadoso planejamento das ati-

Assim também a Chefia de Enfermagem desempenha papel de inegável importânoia: informa a administração sobre a qualidade do cuidado de enfermagem e seu custo, faz cálculo de pessoal necessário, determina as funções de cada categoria profissional (DARCY ${ }^{3}$ ).

A equipe de saúde que será envolvida no processo de mudança deve ser muito bem preparada e orientada quanto à necessidade da utilização do Processo de Enfermagem: a importância de seu uso na identificação dos problemas do paciente e no planejamento de cuidados, a utilidade do Processo de Enfermagem para um cuidado individualizado, como fonte de informação e de pesquisa. 
Devem ser informados das vantagens quanto à racionalização do trabalho que advém do planejamento das ações de enfermagem e melhor aproveitamento do pessoal disponivel.

Assim também o paciente sente que o pessoal de enfermagem está realmente interessado nele como pessoa, não dá margem a que o paciente sinta falta de interesse em si mesmo como ser humano.

A entrevista inicia o relacionamento terapêutico enfermeira-paciente, permite a participação do paciente no planejamento e execução do plano terapêutico de enfermagem.

Com um roteiro planejado obtêm-se geralmente grande quantidade de informações que permitem a identificação dos problemas do paciente e facilita a definição dos objetivos a serem alcançados através do plano terapêutico, o estabelecimento de prioridades e medidas preventivas.

Permite à equipe de saúde um conhecimento mais profundo sobre o paciente levando a um planejamento mais objetivo e à individualização do cuidado com maior segurança.

Permite manter a continuidade das observações, julgamentos, ações e objetivos durante a huspitalização e o seguimento após a alta.

Permite rápida revisão dos dados significativos, o que facilita a comunicação com todos os membros da equipe de saúde, é fonte de informação para estudantes, pesquisadores e professores, além de ser fonte de informações com finalidaçes legais.

A enfermagem está procurando desenvolver suas próprias teorias e organizar um corpo científico de conhecimentos, com a finalidade de fundamentar e sistematizar suas ações. O processo de enfermagem é hoje um dos instrumentos que temos para conseguir esses objetivos.

Encontramo-nos, entretanto, ainda no início de seu desenvolvimento, que demanda paciência e determinação, flexibilidade e espírito critico.

Queremos sempre utilizar o Processo de Enfermagem exatamente como proposto por HORTA, sem levar muito em conta a situação real. É claro que o modelo HORTA deve ser ensinado, pois é o modelo completo, ideal, e portanto deve ser tomado como modelo.

Como tivemos oportunidade de constatar, em nossa Dissertação de Mestrado ${ }^{4}$ a utilização da metodologia do Processo de Enfermagem Dirigido, permite identificar e solucionar maior número de problemas de enfermagem apresentada pelo paciente portador de aneurisma intracraniano na situação de internação.

Queremos agora introduzir a Metodologia de Assistência de Enfermagem aos pacientes internados em Clínica Médica de Hospital-Escola campo de estágio dos alunos do curso de Enfermagem.

Pretendemos com este trabalho oferecer subsídios às enfermeiras que atuam no campo para que elas utilizem uma Metodologia de Assistência de Enfermagem que melhor atenda às necessidades dos pacientes sob sua responsabilidade. 
Assim também pretendemos contribuir para o progresso do ensino de Fundamentos de Enfermagem e Enfermagem Médico-Cirúrgica e melhorar a qualidade da Assistência de Enfermagem prestada aos pacientes sob nossa responsabilidade.

\section{Objetivo}

Introduzir a Metodologia de Assistência de Enfermagem em Clínica Médica em Hospital-Escola, campo de estágio dos alunos do curso de graduação em Enfermagem nos $2^{\circ}$ e $4^{\circ}$ anos.

\section{Hipótese}

- É possivel aplicar uma Metodologia de Assistência de Enfermagem simplificada e adaptada às condiçôes materiais e humanas disponiveis.

- A utilização de uma Metodologia de Assistência melhora a qualidade do cuidado prestado.

- A utilização de Metodologia de Assistência contribui para uma objetividade maior e um embasamento científico do ensino de enfermagem.

\section{Metodologia}

Com a finalidade de padronizar a assistência de enfermagem prestada aos pacientes internados no Hospital em estudo, e de melhorar a qualidade de ensino de Metodologia de Assistência aos alunos do curso de Graduação em Enfermagem foi criada uma comissão de Estudos de Metodologia de Assistência de Enfermagem composta por enfermeiros integrantes das disciplinas de Fundamentos de Enfermagem, Enfermagem Médico-Cirúrgica, Saúde Pública, Materno-Infantil e pela Coordenadora do curso de Enfermagem.

Essa comissão tinha por objetivos:

1.0 Criar uma metodologia de assistência de enfermagem adequada aos recursos existentes no Hospital-Escola.

2.0 Melhorar a qualidade da assistência de enfermagem prestada aos pacientes internados. Escola.

3.0 Melhorar o método de trabalho das enfermeiras no Hospital-

4.0 Aprimorar o ensino.

5.0 Desenvolver futuras pesquisas.

A comissão reuniu-se por quatro vezes para o estudo do Processo de Enfermagem e a seleção das fases viáveis com os recursos disponiveis, e para a elaboração de um instrumento de coleta de dados (anexo 1) e respectivo manual de instruções para seu preenchimento (anexo 2).

Baseados na Bibliografia disponível e na experiência pessoal dos membros da comissão, slaborou-se um instrumento de coleta de dados 
de Identificação, informações gerais, exame físico geral e específico, denominado Histórico de Enfermagem.

No verso do Histórico há um espaço denominado Listagem de Problemas onde devem ser anotados os problemas encontrados durante a entrevista e anexados àqueles encontrados no decorrer do tratamento. Quando de sua solução os problemas são checados.

Com base nos problemas encontrados é elaborada a Prescrição de Enfermagem.

Diariamente é feita a evolução de enfermagem, quando se examina o estado atual da paciente em comparação com seu estado no dia anterior.

\section{Pré-teste}

Para o pré-teste a metodologia de assistência foi aplicada para dez pacientes internados nas Clínicas Médica, Cirúrgica, Maternidade, Pediatria e Pronto-Socorro, num total de cinqüenta pacientes.

Para efeito do pré-teste utilizamos uma folha de prescrição e evolução de enfermagem separada do impresso em uso no Hospital (anexo 3)..

Foram escolhidos os pacientes com admissão recente e o estudo se estendeu por cinco dias de segunda à sexta-feira.

A Clínica Médica e a Clínica Cirúrgica aplicaram para dez pacientes cada uma, Pediatria oito paciente, Obstetrícia oito pacientes e Pronto-Socorro seis pacientes.

Após esse periodo a comissão se reuniu novamente para avaliar as dificuldades e as falhas encontradas no instrumento de coleta de dados.

Foram citadas as seguintes dificuldades:

- Tempo gasto na coleta de dados e prescrição de enfermagem;

- Falta de pessoal para cumprir a prescrição de enfermagem;

- Falta de orientação da pessoa que aplica a metodologia;

- Não comparecimento da mãe na visita, impedindo a obtenção de algumas informações na Unidade de Pediatria;

- Dinâmica de trabalho de Unidades como Pronto-Socorro.

No instrumento de coleta de dados foi acrescentado um espaço para anotar o diagnóstico médico e para informaçōes sobre alimentação. Para alguns itens foi aumentado o espaço para anotação da informação.

Em lugar de "Entrevistado", optou-se por "dados fornecidos por..."

A Unidade de Pronto-Socorro testou a Metodologia por mais cinco dias para completar os dez pacientes.

Após esse periodo as dificuldades encontradas foram as já citadas. Em reunião da comissão decidiu-se implantar a Metodologia nas áreas 
já citadas, exceto no Pronto-Socorro, para todos os pacientes admitidos at partir da data de implantação do novo sistema de Prontuários em estudo na Instituição.

Na semana seguinte a comissão se reuniu para revisão do trabalho já feito e informação a algumas enfermeiras da comissão que estiveram afastadas.

Nessa ocasião discutiram-se os problemas para a implantação da nova Metodologia:

1. As enfermeiras na Instituição estão contratadas para quarenta horas semanais, trabalhando oito horas diárias de segunda à sexta-feira, tendo atividades docentes e assistenciais, pois cada uma é responsável por uma das Unidades de internação do hospital, ministram aulas no Curso de Enfermagem e acompanham estágio dos alunos de graduação em sua Unidade. Dessa forma surgiu o problema do acompanhamento do paciente nos finais de semana, férias e feriados uma vez que nesses períodos, responde pela administração das Unidades um auxiliar de enfermagem treinado.

2. O período da tarde (após às quinze horas) e o noturno também ficam descobertos, embora já esteja no planejamento a contratação de enfermeiras para esses períodos.

3. Os alunos de administração em enfermagem devem ser treinados para essa nova atividade e assim poder dividir com a enfermeira as tarefas de coleta de dados e prescrição de enfermagem.

A comissão decidiu que enquanto esses novos profissionais não fossem contratados e enquanto não houvesse enfermeiras para cobrir os finais de semana, férias e feriados, não haveria possibilidade de implantação da nova metodologia e dessa forma dissolveu-se a comissão.

Nós sentimos, entretanto, uma necessidade imperiosa de não deixar perder todo o trabalho até então realizado, e de motivar e envolver os alunos de graduação para um atendimento de enfermagem planejado e cientificamente embasado.

Assim também sentimos a necessidade de melhorar a qualidade da assistência de enfermagem prestada aos pacientes sob nossa responsabilidade.

A Unidade sob nossa responsabilidade é a Clínica Médica Feminina com vinte e dois leitos de internação e mais dois de diálise peritonial. Para a Unidade contamos com dois atendentes de enfermagem em cada periodo de doze horas. Para a Diálise contamos com um atendente para cada período de doze horas.

Durante três meses de trabalho nessa Unidade detectamos algumas falhas técnicas e administrativas que procuramos corrigir com o objetivo de preparar o campo para a implantação da metodologia proposta e melhorar o ensino. 
Com a colaboração da aluna em estágio de Administração preparamos exposiçōes rápidas durante a passagem de plantão abordando as técnicas que estavam mais falhas: optamos pela passagem de plantão pela possibilidade de reunir dois grupos de funcionários sem interferir no periodo de descanso.

Assim, por exemplo, a anotação de enfermagem era quase inexistente, constando apenas os resultados do controle de sinais vitais e diurese. Havia porém o "Livro de Plantão", onde algumas ocorrências com o paciente eram anotadas.

Durante uma semana fizemos um treinamento com os funcionários sobre o que anotar e como anotar. Diariamente as anotações eram analisadas e discutidas. Ao final desse periodo, suspendemos as anotações no "Livro de Plantão", permanecendo este apenas para fins estatísticos e de consutla.

Com relação à Equipe Médica, em reunião do Departamento de Clínica Médica foi exposto aos professores e residentes toda a Metodologia a ser empregada.

Solicitando e obtendo a colaboração de uma colega da disciplina de Fundamentos de Enfermagem e Enfermagem Médico-Cirúrgica, iniciamos a aplicação da Metodologia de Assistência de Enfermagem par'a todos os pacientes internados a partir de 1-7-85 na Clínica Médica Feminina. Utilizamos para isso um impresso provisório para prescrição de enfermagem até que obtivéssemos o adequado treinamento das enfermeiras e dos funcionários.

Assim como o instrumento de coleta de dados foi simplificado para atender as exigências de tempo e treinamento das enfermeiras, também a prescrição de enfermagem foi simplificada e adaptada aos recursos humanos e materiais disponiveis. Assim prescreve-se higiene oral pela manhã e após o jantar, mudança de decúbito apenas quatro vezes ao dia.

Os alunos do $2^{\circ}$ ano de Graduação em Enfermagem tomaram parte no trabalho fazendo Histórico de Enfermagem, Evolução e Prescrição. $\mathrm{O}$ aluno em estágio de administração, auxiliava na supervisão de alunos do $2^{\circ}$ ano e de funcionários e dividia com as enfermeiras as prescrições de finais de semana e feriados.

Durante o mês seguinte elaborou-se uma falha de prescrição única (anexo 4) e após aprovação pelo CTA foi oficialmente introduzida a partir de cinco de setembro.

No periodo de quinze de agosto à cinco de dezembro estivemos afastados para elaboração e defesa dos Exames de Qualificação, ficando o trabalho sob responsabilidade da enfermeira colaboradora. Entretanto periodicamente checamos o andamento do trabalho, esclarecendo as dúvidas dos alunos e funcionários, e avaliando com a enfermeira colaboradora as dificuldades $e$ as eventuais mudanças. 
No final do estágio do grupo de Médico Cirúrgica sentimos a necessidade de uma avaliação por parte dos alunos sobre o nosso trabalho.

Assim elaboramos um questionário com o objetivo de verificar a importância da Metodologia de Assistência de Enfermagem para os alunos do $2^{\circ}$ ano do curso de graduação em estágio de Enfermagem Médico-Cirúrgica na Clínica Médica (anexo II).

No final de 1985 a clínica sofreu algumas alterações. O número de leitos caiu para dezoito. Foi aberta em uma enfermaria de quatro leitos uma sala de Cuidados Especiais onde são agrupados pacientes graves que necessitam cuidados intensivos. Esses pacientes são cuidados por um auxiliar de enfermagem em plantōes de seis horas durante o dia e doze/trinta e seis durante a noite. Naquela sala recebemos pacientes de todas as Unidades do Hospital, exceto de Pediatria.

Consideramos que, mesmo recebendo pacientes de Unidades onde a Metodologia de Assistência não teria continuidade, por tratar-se de pacientes graves exigindo especial assistência de enfermagem deveríamos incluir estes pacientes em nosso trabalho, embora na maioria das vezes a prescrição se baseie unicamente no exame físico, pela impossibilidade de obter outros dados.

A partir de maio de 1986 obtivemos mais um funcionário trabalhando oito horas diárias de segunda à sexta-feira, quando há maior trabalho burocrático e de encaminhamento.

Os alunos de Fundamentos de Enfermagem, são introduzidos no Processo de Enfermagem segundo o modelo HORTA.

Pensamos então em iniciar os alunos em estágio de Fundamentos de Enfermagem em nossa clínica, na Metodologia por nós utilizada.

Assim, a partir da terceira semana de estágio quando os alunos já estavam familiarizados com as rotinas do hospital, já mantinham um entrosamento com os colegas, funcionários e supervisor, já tinham superado o receio natural de iniciar um relacionamento com o paciente, iniciamos a participação destes alunos na Metodologia empregada na Unidade.

Cada aluno é responsável por dois leitos da Unidade. Quando há internação o aluno responsável pelo leito faz o Histórico de Enfermagem e a prescrição pertinente àquele paciente admitido.

Baseado no histórico já existente, no exame físico diário e na evolução o aluno faz diariamente a prescrição de enfermagem dos pacientes sob seus cuidados. Inicialmente tanto o histórico como a prescrição era feito em rascunho, corrigida pelo supervisor e depois passada para a folha de prescrição.

Atualmente, conforme sugestões dos alunos de Fundamentos de Enfermagem, Enfermagem Médico-cirúrgica, e Administração em Enfermagem, e da nossa própria necessidade, estamos em fase de elaboração de um novo Histórico de Enfermagem, que nos forneça mais dados sócio-econômico-culturais e de exame físico. 


\section{BIBLIOGRAFIA}

1. ASHWORTH, P. Problems and solutions. Nurs Mirror, 151(10) :34-36, Sept. 1980.

2. COWPER-SMITH, F. What is the point of the nursing process. Murs. Times. London, $74(18): 738-9,4$ May 1978.

3. DARCY, P.T. The nursing process: a base for all nursing developments. Murs. Times. London, $76(12): 497-50,20$ Mar. 1980.

4. FERNANDES, M.A. Tratamento de enfermagem de pacientes portadores de aneurisma intracraniano não operado através da aplicação do processo de enfermagem dírigido. Dissertação de Mestrado apresentada à Escola de Enfermagem da USP. São Paulo, 1982.

5. horta, W. de A. \& CAStellanos, B.P. Processo de Enfermagem. São Paulo, EPU, 1979.

6. LEWIS, L. This I belleve. Nurs Outlook, 16(5):26-29, May 1986. 


\section{ANEXXO I \\ HISTORICO DE ENFERMAGEM}

\section{I - Identificagio}

Nome:

Leito

Data da Entrevista:

Entrevistador:

Dados fornecidos por: Diagnóstico:

\section{II - Informacóes Gerals}

1 - Exame médico periodo; motivo:

2 - Alergia a drogas:

3 - Alergia a alimentos:

4 - Hábitos de vida diária:

Posiçăo que ocupa na famillia

Religiåa

Sono e Repouso

Eliminaçðes

Atividade sexual

Fumo e bebida alcoolica

Alimentação

Outros

\section{III - Exame Fisico}

1 - Sinais Vitais: $T=$ Observaçzes:

$\mathbf{P A}=$

$\mathbf{P}=$

$\mathbf{R}=$

2 - Informaçбes e Observaçōes Gerals:

Cabeça:

Tórax:

Abdomem:

Genitália Externa:

Membros Superiores:

Membros Inferiores:

3 - Informaçðes e Observaç̋es Especificas: 


\section{INSTRUMENTO PARA COLETA DE DADOS}

NOME: (optativo)

Com a utilização da Metođologia de Assistência de Enfermagem na Unidade de Clínica Médica Feminina do H.C. da Famema, responda:

1. Contribui para uma melhor assistência ao paciente? Sim, Não, Porque?

2. Contribui para uma melhor aprendizagem. Sim, Não, Porque?

3. Quais as vantagens na utilização da Metodologia de Assistência de Enfermagem?

4. Quais as desvantagens na utilização da Metodologia de Assistência de Enfermagem?

5. Sugestões quanto a aplicação da Metodologia de Assistência de Enfermagem. 


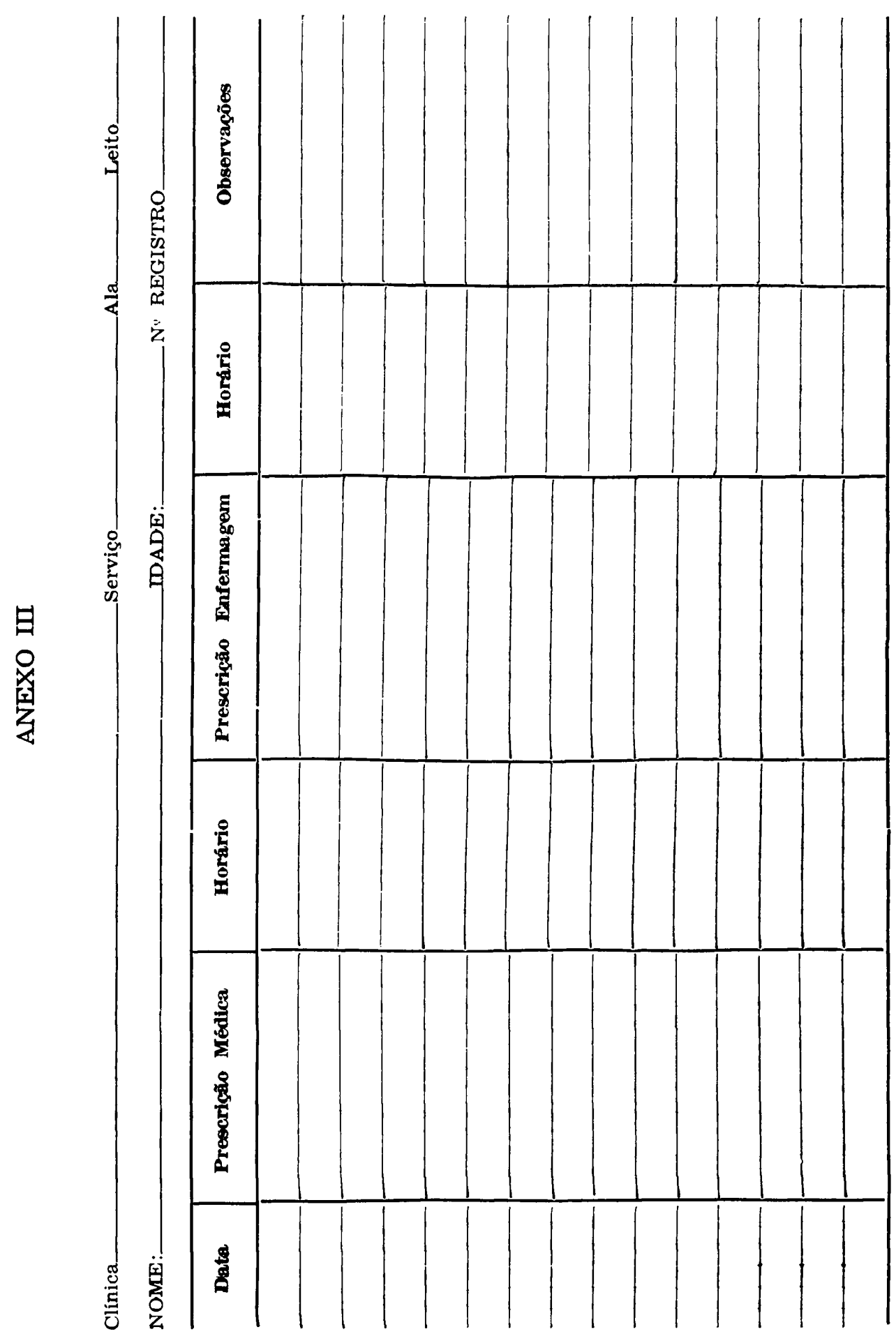

Rev. Esc. Enf. USP, São Paulo, 21 (no especial) :88-99, jun. 1987. 